\title{
Surgical Management of Freiberg Disease by Dorsal Closing Wedge Osteotomy
}

\author{
Dhar SA, MS, Mir NA, MS, Dar TA, MS \\ Department of Orthopaedics, Sher - i - Kashmir Institute of Medical Sciences (SKIMS) Medical College Bemina, \\ Srinagar, India \\ This is an open-access article distributed under the terms of the Creative Commons Attribution License, which permits unrestricted use, \\ distribution, and reproduction in any medium, provided the original work is properly cited \\ Date of submission: 03rd May 2019 \\ Date of acceptance: 16th April 2020
}

\begin{abstract}
Introduction: The purpose of the study was to assess the efficacy of the dorsal closing wedge osteotomy for the treatment of Freiburg's infraction.

Material and Methods: Twenty patients with Freiburg's infraction were admitted at our hospital over a period of six years. Patients with a normal plantar contour of the metatarsal head were included. All patients underwent a dorsal closing wedge osteotomy of the metatarsal.

Results: The mean Leeds Movement Performance Index (LMPI) score was 84 (range 70-86). The mean metatarsal shortening was $2 \mathrm{~mm}$. the passive flexion restriction was $16^{\circ}$ and extension restriction was $10^{\circ}$. Also, a strong negative correlation was found between Smillie classification and American Orthopaedic Foot and Ankle Score (AOFAS) final score (r's $=-0.85, \mathrm{P}<.001)$.

Conclusion: The dorsal closing wedge osteotomy is an efficient and reproducible method for the management of Freiburg's infraction.
\end{abstract}

Keywords:

Freiburg infraction, osteotomy

\section{INTRODUCTION}

The Freiberg's infraction is the painful collapse of the articular surface of the metatarsal head (Fig. 1) ${ }^{1}$. The disease affects females predominantly ${ }^{2}$. The second metatarsal is most commonly affected ${ }^{3}$. Various theories have been proposed in the etiology of this disease. These include injury to the vascular supply of the metatarsal head and trauma which may be a single event or a repetitive phenomenon ${ }^{4,5}$. The patients tend to report pain on walking or a feeling of a small hard object under the sole of the foot. Freiberg's infraction can be treated conservatively if detected early, but late presentation may have to be managed by surgery ${ }^{6}$.
Several conservative methods have been used in the management of Freiberg's infraction. These are activity modification, insoles, metatarsal pads, casting and controlled ankle motion boots? ${ }^{7}$. Surgical interventions include debridement, bone grafting, interpositional arthroplasty, core decompression or joint replacement ${ }^{8}$. One of the methods used for the management of Freiberg's infraction is the dorsiflexion osteotomy of the metatarsal neck which rotates the cartilage facing plantarwards into the joint thus improving the arthrosis.

This study reports the results of this procedure done on 20 patients over a five years period in our department.

\section{MATERIALS AND METHODS}

Twenty patients presenting to the outpatient department (OPD) of the SKIMS Medical College Bemina were assessed to have stage 4 and 5 Smillie grade infraction with good plantar contour and cartilage of the metatarsal head. Under anaesthesia, an incision $(3.5 \mathrm{~cm})$ was made dorsomedial to the extensor digitorum longus tendon from the metatarsal neck to the base of the phalanx. Superficial and deep fascia were dissected carefully and the extensor tendon was retracted laterally. The capsule was opened dorsally in a longitudinal fashion followed by a cheilectomy and synovectomy (Fig. 2). A wedge-shaped osteotomy was done with the distal cut being made $2-3 \mathrm{~mm}$ proximal to the unhealthy part and the distal fragment was rotated dorsally so that the volar surface is brought distally (Fig. 3). We used a K-wire as a joystick to control the distal fragment into a proper position as it is difficult to control the distal fragment otherwise. The angle of the osteotomy was $15^{\circ}$ but was increased if the rotation required was more. The osteotomy was held by one or two k-wires. The k-wire/wires were removed at six weeks. 
Table I: The pre-operative and post-operative assessment

\begin{tabular}{|c|c|c|c|c|c|c|c|c|}
\hline S No & Age & Side & $\begin{array}{l}\text { Metatarsal } \\
\text { affected }\end{array}$ & $\begin{array}{c}\text { Stage } \\
\text { (Smillie) }\end{array}$ & $\begin{array}{c}\text { Symptoms } \\
\text { (Pre-operation) }\end{array}$ & $\begin{array}{l}\text { Shortening } \\
\quad(\mathrm{mm})\end{array}$ & $\begin{array}{l}\text { Range of } \\
\text { motion } \\
\text { Pre / Post }\end{array}$ & $\begin{array}{l}\text { LMPI score } \\
\text { Pre / Post }\end{array}$ \\
\hline 1. & 19 & $\mathrm{R}$ & 2 & 5 & pain/ hard object & 1 & $40 / 60$ & $52 / 70$ \\
\hline 2. & 23 & $\mathrm{~L}$ & 2 & 4 & pain & 4 & $20 / 40$ & $57 / 86$ \\
\hline 3. & 18 & $\mathrm{~L}$ & 2 & 4 & pain & 2 & $25 / 40$ & $62 / 80$ \\
\hline 4. & 27 & $\mathrm{~L}$ & 2 & 4 & pain & 2 & $25 / 35$ & $57 / 80$ \\
\hline 5. & 34 & $\mathrm{~L}$ & 3 & 4 & pain & 2 & $25 / 40$ & $72 / 82$ \\
\hline 6. & 30 & $\mathrm{R}$ & 2 & 4 & pain & 1 & $30 / 50$ & $75 / 85$ \\
\hline 7. & 17 & $\mathrm{R}$ & 2 & 4 & pain & 1 & $35 / 50$ & $72 / 86$ \\
\hline 8. & 17 & $\mathrm{~L}$ & 2 & 5 & pain/ hard object & 1 & $30 / 40$ & $57 / 80$ \\
\hline 9. & 17 & $\mathrm{R}$ & 2 & 5 & pain & 1 & $25 / 40$ & $62 / 86$ \\
\hline 10. & 23 & $\mathrm{~L}$ & 3 & 5 & pain & 2 & $25 / 40$ & $75 / 86$ \\
\hline 11. & 28 & $\mathrm{~L}$ & 2 & 4 & pain & 2 & $30 / 60$ & $27 / 84$ \\
\hline 12. & 33 & $\mathrm{R}$ & 3 & 4 & pain & 1 & $25 / 40$ & $57 / 84$ \\
\hline 13. & 26 & $\mathrm{R}$ & 2 & 4 & pain & 2 & $30 / 55$ & $62 / 84$ \\
\hline 14. & 32 & $\mathrm{R}$ & 2 & 5 & pain & 4 & $20 / 40$ & $57 / 86$ \\
\hline 15. & 19 & $\mathrm{R}$ & 2 & 5 & pain & 3 & $35 / 55$ & $62 / 85$ \\
\hline 16. & 20 & $\mathrm{~L}$ & 3 & 5 & pain & 1 & $25 / 40$ & $27 / 85$ \\
\hline 17. & 21 & $\mathrm{R}$ & 2 & 5 & pain & 1 & $30 / 45$ & $62 / 85$ \\
\hline 18. & 19 & $\mathrm{R}$ & 2 & 4 & pain & 1 & $30 / 60$ & $57 / 86$ \\
\hline 19. & 16 & $\mathrm{~L}$ & 2 & 4 & pain & 1 & $25 / 40$ & $57 / 86$ \\
\hline 20. & 16 & $\mathrm{~L}$ & 2 & 5 & pain/ hard object & 2 & $30 / 55$ & $62 / 86$ \\
\hline
\end{tabular}

Table II: Smillie staged the osteochondrosis into five stages ${ }^{13}$

\begin{tabular}{|l|}
\hline Smillie staging \\
\hline 1. Fissure type fractures in an ischaemic epiphysis. \\
2. Altered articular contour of the dorsal and central part of the head \\
3. Altered articular contour with widening and subchondral cystic changes. \\
4. Presence of loose bodies. \\
5. Complete metatarsal head flattening and a deforming arthrosis. \\
\hline
\end{tabular}

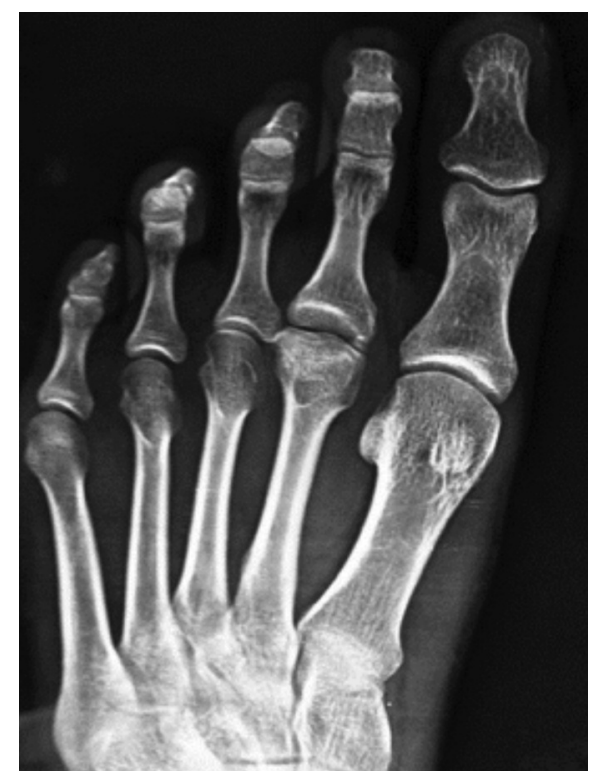

Fig. 1: Freiburg's infraction of the second metatarsal.

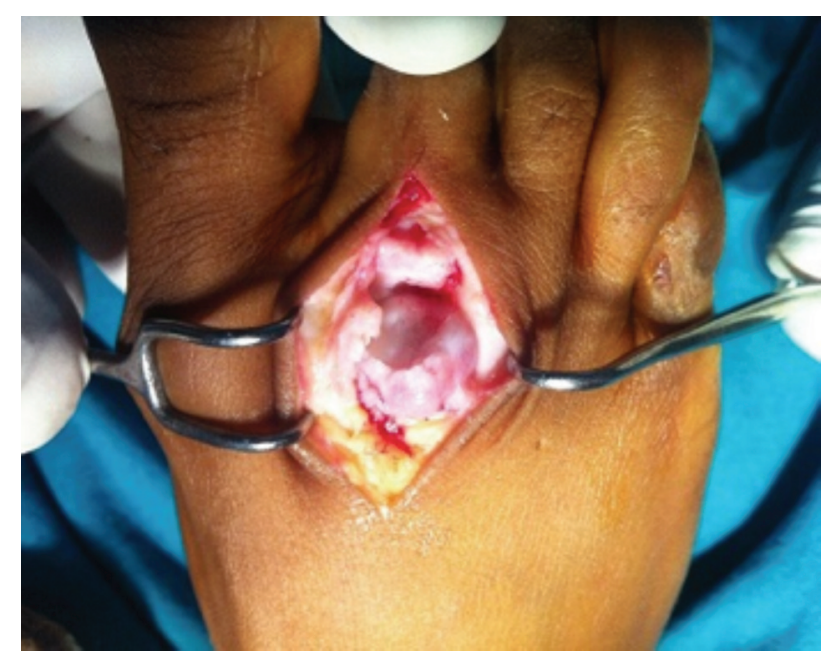

Fig. 2: The damaged distal part of the head of the metatarsal. 


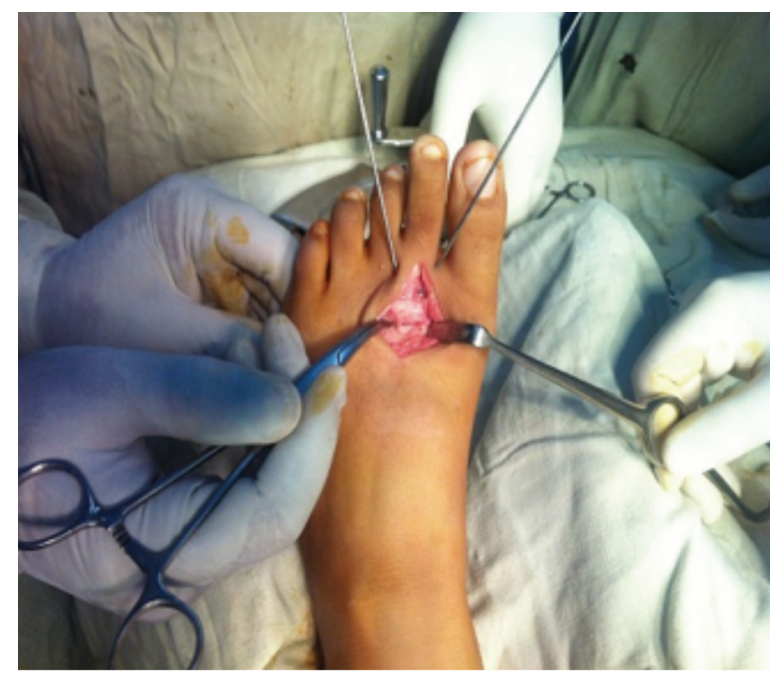

Fig. 3: The closed osteotomy.
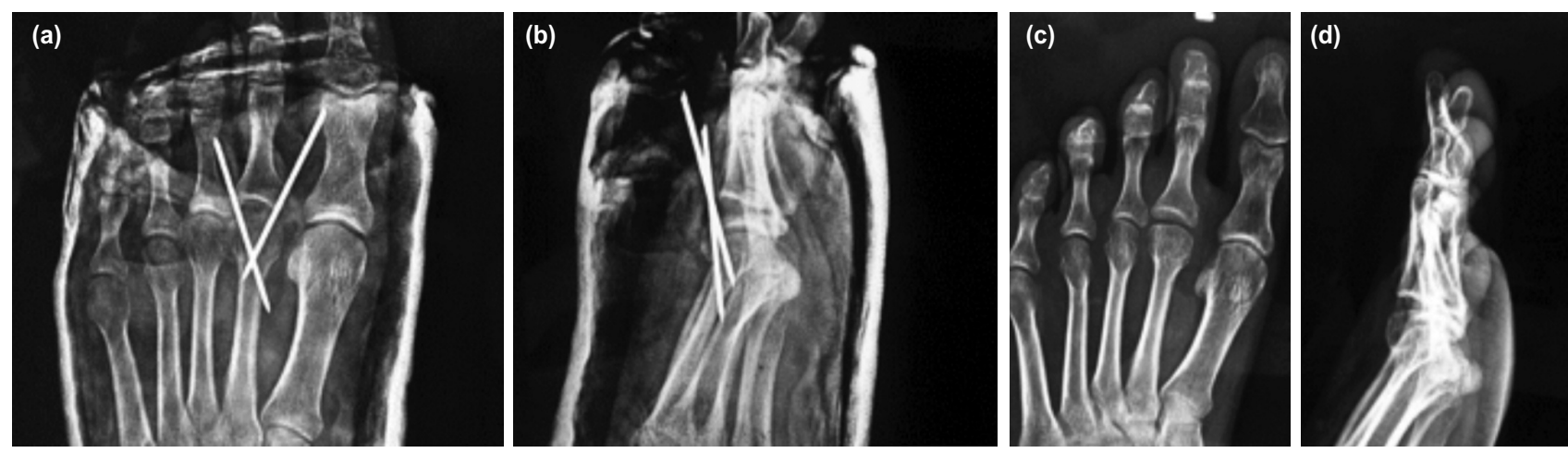

Fig. 4: Post-operative radiographs; (a) anteroposterior, (b) lateral. Radiograph at final follow-up (c) anteroposterior and (d) lateral views.

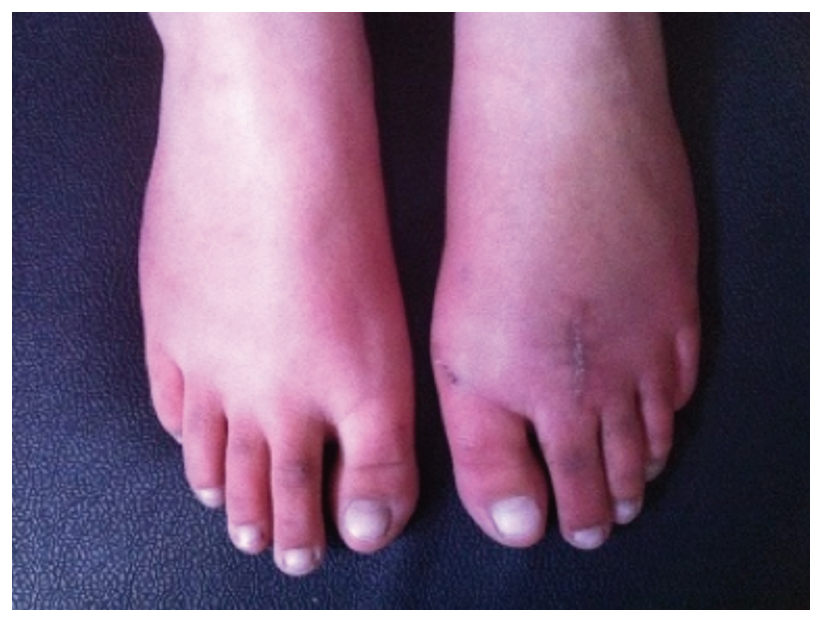

Fig. 5: Clinical picture with mild shortening.
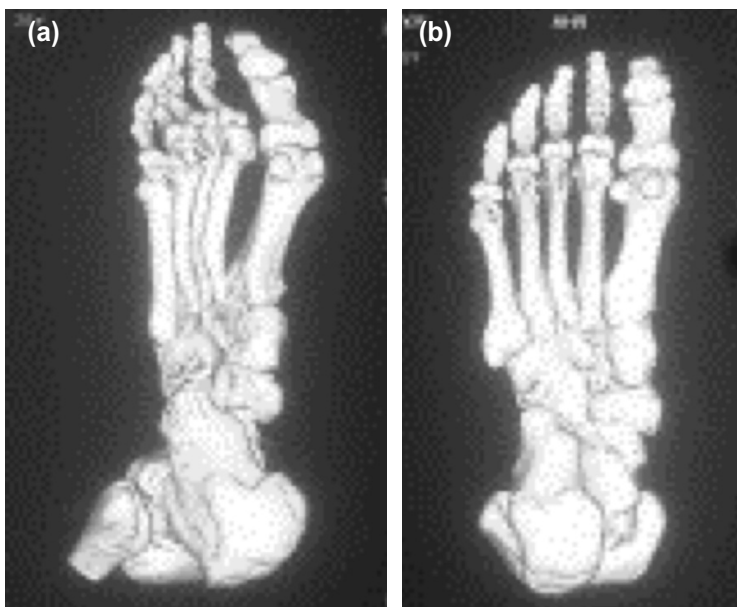

Fig. 6: The shaded surface display on CT scan showing a good plantar contour of the second metatarsal; (a) oblique view and (b) inferior view. 

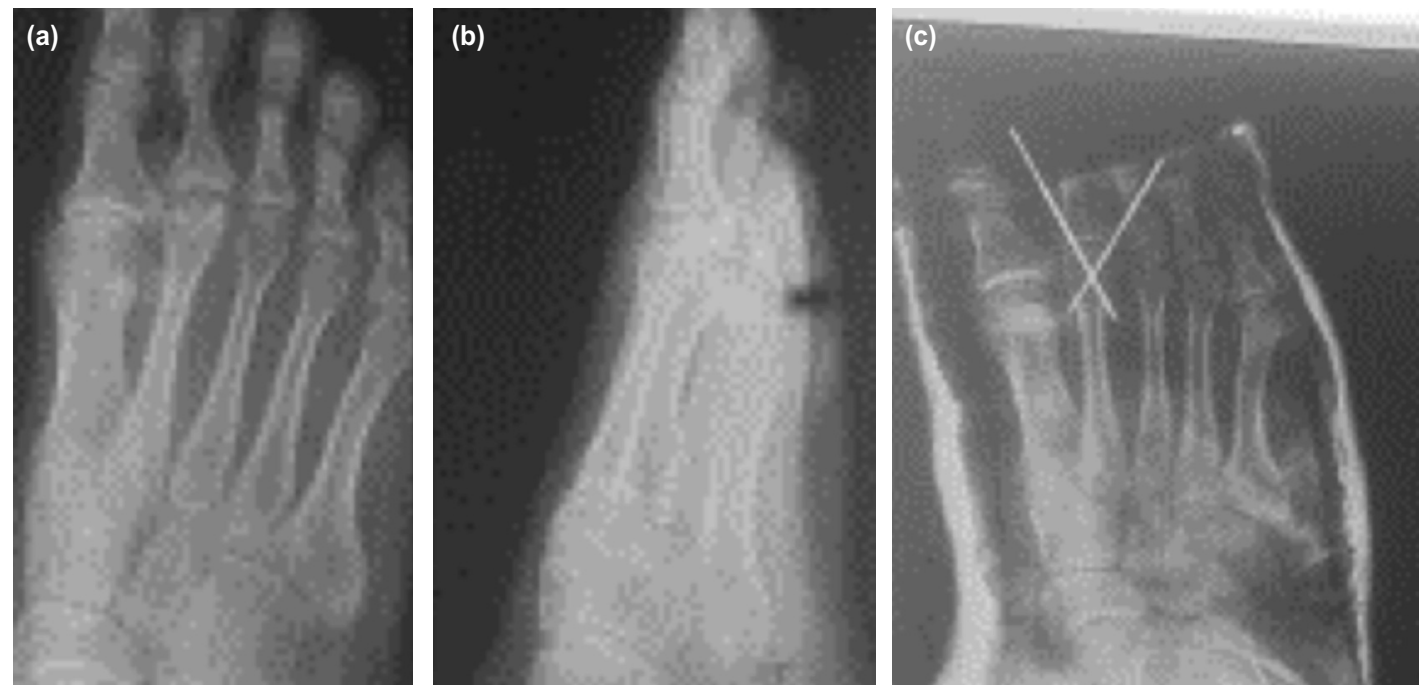

Fig. 7: The radiographs show osteotomy where no debridement was done; (a) anteroposterior view, (b) lateral view and (c) postoperative view.

\section{RESULTS}

The average follow-up of the patients was 12 to 60 months. All cases united at six weeks but protected weight bearing was continued for 12 weeks (Fig. 4 and 5). The average metatarsal shortening was $1.75 \mathrm{~mm}$ (range of $1-4 \mathrm{~mm}$ ) due to the osteotomy. The results were graded as per the LMPI scale which allots 40 points to pain, 45 points to function and 15 points to function (maximum 100 points) 9 . The mean LMPI score was 84 (range 70-86). The mean metatarsal shortening was $2 \mathrm{~mm}$, the passive flexion restriction was $16^{\circ}$ and extension restriction was $10^{\circ}$ (Table I).

Also, a strong negative correlation was found between Smillie classification and AOFAS final score ( $\mathrm{r}$ 's $=-0.85, \mathrm{P}$ $<.001$ ) (Table II).

\section{DISCUSSION}

Freiberg's infraction is the second most common osteochondrosis of the foot. The disease has also been referred to as 'egg shell fracture', 'metatarsal epiphysitis', 'osteochondritis deformans metatarsojuvenilis' and 'malakopathie'10,11. This probably points to the persistent debate over the etiology of the disease.

Freiberg's infraction is always situated at the front, dorsal part of the metatarsal head, and is considered to be a dorsal trabecular stress injury of the second or the third metatarsal head. Excessive pressure on the metatarsal head during weight bearing could cause repetitive microfracture, loss of blood supply to the subchondral bone, collapse of the cancellous bone, and cartilage deformation ${ }^{12}$.

Smillie staged the osteochondrosis into five stages ${ }^{13}$. First, fissure type fractures in an ischaemic epiphysis. Second, altered articular contour of the dorsal and central part of the head. Third, altered articular contour with widening and subchondral cystic changes. Fourth, presence of loose bodies and fifth, complete metatarsal head flattening and a deforming arthrosis.

The recommended method of treatment of stages 4 and 5 is surgery. The goal is to restore joint congruence and motion ${ }^{14}$.

Some surgical procedures are fraught with complications. Resection arthroplasty can cause transfer metatarsalgia. Should conservative treatment fail, a wide variety of surgical procedures exist; however, the optimal procedure is unknown. A review published in 2015 reported that only 257 joint sparing procedures have been reported in literature pointing to a relative paucity of literature in this regard ${ }^{15}$.

The extent of necrosis is the main determining factor in the outcome of osteonecrosis. There is no method for measuring the extent of osteonecrosis of the metatarsal head in Freiberg's infraction. The use of CT scanning helps in assessment of the extent and allows the surgeon to plan a procedure in a better manner (Fig. 6) ${ }^{16}$.

Dorsal closing wedge osteotomy was reported by Gauthier et $a l^{3}$. Some series have been reported since with the partial modification of replacing the cerclage wire used originally by a k-wire ${ }^{17,18,19}$. The dorsiflexion osteotomy realigns the intact plantar metatarsal cartilage and hence provides a more physiological joint congruence and motion. The procedure also allows decompression with minimal shortening. Gauthier and Elbaz removed unhealthy tissue during dorsal wedge closing osteotomy, but it has been found that the remaining intact portion of the metatarsal head was too small for internal fixation to be performed. Thus, the osteotomy site is moved more proximally to allow a better purchase and 
fixation. We did not debride the lesion in any of our cases (Fig. 7).

This technique has good results, and its complications are in most cases related to the use of osteosyntesis material. With the development of percutaneous surgery, this wedge osteotomy could be performed through a minimal incision, reducing morbidity. The procedure is also reproducible and the use of a k-wire allows removal of hardware on an outpatient department basis.

\section{CONCLUSION}

The dorsal closing wedge osteotomy is an efficient and reproducible method for the management of Freiburg's infraction.

\section{CONFLICT OF INTEREST}

The authors declare no potential conflict of interest.

\section{ACKNOWLEDGEMENT}

We would like to acknowledge the contributions of Dr Muzaffar Mushtaq, Senior Resident (SKIMS MC Bemina), in the preparation of this manuscript.

\section{REFERENCES}

1. Freiberg AH. Infraction of the second metatarsal bone, a typical injury. Surg Gyn Ob. 1914; 19: 191.

2. Katcherian DA. Treatment of Freiberg's disease. Orthop Clin North Am. 1994; 25(1): 69-81.

3. Gauthier G, Elbaz R. Freiberg's infraction: a subchondral bone fatigue fracture. A new surgical treatment. Clin Orthop Relat Res. 1979; (142): 93-5.

4. Wiley JJ, Thurston P. Freiberg's disease. J Bone Joint Surg. 1981; 63-B: 459.

5. Murphy GA. Lesser toe anomalies. In: Canale ST, Beaty JH, editors. Campbell's Operative Orthopaedics. 12th ed. Philadelphia: Elsevier Mosby; 2012. p. 4018-20.

6. Faircloth J, Mitchell JJ, Edwards DS. Late Stage Freiberg Infraction in a Division I Collegiate Tennis Player. J Orthop Case Rep. 2015; 5(3): 12-14. doi: 10.13107/jocr.2250-0685.295.

7. Love JN, O'Mara S. Freiberg's disease in the emergency department. J Emerg Med. 2010; 38(4); e23-5. doi: 10.1016/j.jemermed.2007.10.028

8. Waldman SD, Campbell RSD. Imaging of pain. Philadelphia: Saunders Elsevier; 2011. Chapter 174, Freiberg's Disease; p. 447-8.

9. Kitaoka HB, Alexander IJ, Adelaar RS, Nunley JA, Myerson MS, Sanders M. Clinical rating systems for the ankle-hindfoot, midfoot, hallux and lesser toes. Foot Ankle Int. 1994; 15:349-53. doi: 10.1177/107110079401500701

10. Cerrato RA. Freiberg's Disease. Foot Ankle Clin. 2011; 16(4): 647-58. doi: 10.1016/j.fcl.2011.08.008

11. Carmont MR, Rees RJ, Blundell CM. Current Concepts Review: Freiberg's Disease. Foot Ankle Int. 2009; 30(2): 167-76. doi: 10.3113/FAI-2009-0167

12. Murphy AG, Richardson GE. Lesser toe abnormalities. In: Canale ST, Campbell WC, editors. Campbell's Operative Orthopaedics. 9th ed. St Louis: Mosby; 1998. p. 1779-81.

13. Smillie IS. Treatment of Freiberg's Infraction. Proc R Soc Med. 1967; 60: 29-31.

14. Miyamoto W, Takao M, Uchio Y, Kono T, Ochi M. Late Stage Freiberg Disease Treated by Osteochondral Plug Transplantation: A Case Series. Foot Ankle Int. 2008; 29: 950-5. doi: 10.3113/FAI.2008.0950

15. Schade VL. Surgical Management of Freiberg's Infraction: A Systematic Review. Foot Ankle Spec. 2015; 8(6): 498-519. doi: $10.1177 / 1938640015585966$

16. Chun KA, Oh HK, Wang KH, Suh JS. Freiberg's Disease: Quantitative Assessment of Osteonecrosis on Three-Dimensional C. J Am Podiatr Med Assoc. 2011; 101(4): 335-40. doi: 10.7547/1010335

17. Ozkul E, Gem M, Alemdar C, Arslan H, Bogatekin F, Kisin B. Results of two different surgical techniques in the treatment of advanced-stage Freiberg's disease. Indian J Orthop. 2016; 50: 70-3. doi: 10.4103/0019-5413.173514

18. Hofstaetter SG, Hofstaetter JG, Petroutsas JA, Gruber F, Ritschl P, Trnka HJ. The Weil osteotomy: A seven-year follow-up. $J$ Bone Joint Surg Br. 2005; 87(11): 1507-11. doi: 10.1302/0301-620X.87B11.16590

19. Kinnard P, Lirrete R. Freiberg's disease and dorsiflexion osteotomy. J Bone Joint Surg Br. 1991; 73(5); 854-5. 